S. N. SALEM AND S. C. TRUELOVE: DISSECTING MICROSCOPE APPEARANCES OF GASTRIC MUCOSA
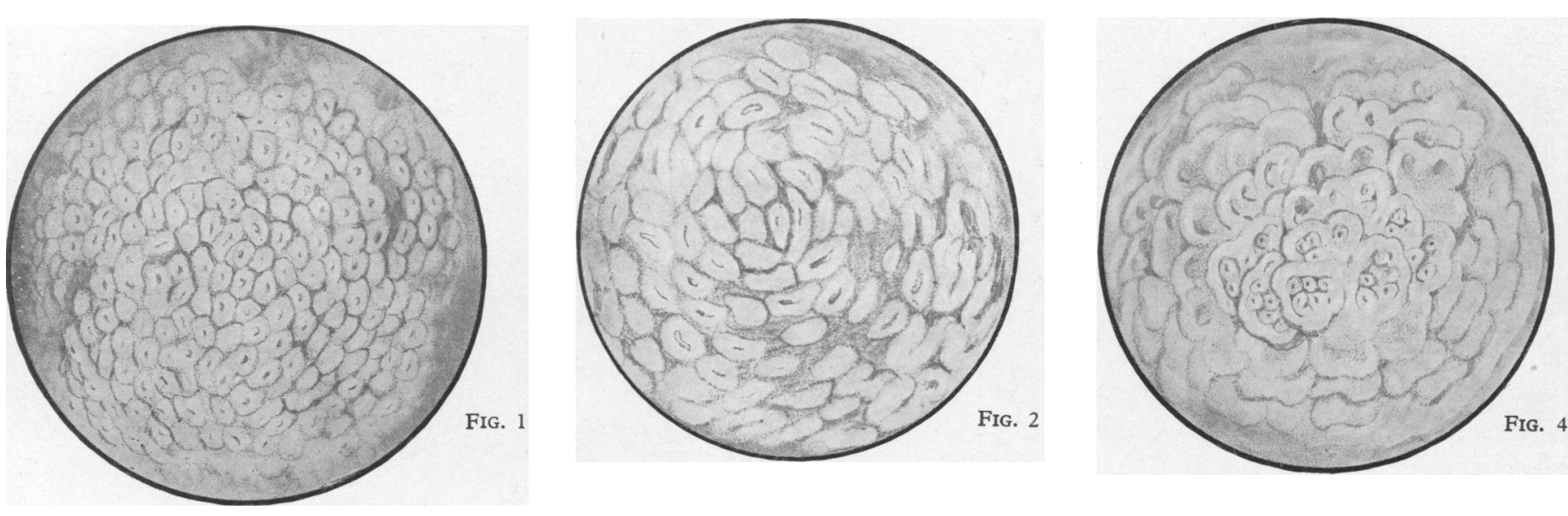

FIG. 1.-Normal fundic mucosa (artist's drawing).

FIG. 2.-Fundic mucosa in superficial gastritis (artist's

FIG. 3.-Fundic mucosa in atrophic gastritis (artist's drawing).

FIG. 4.-Normal pyloric mucosa (artist's drawing).
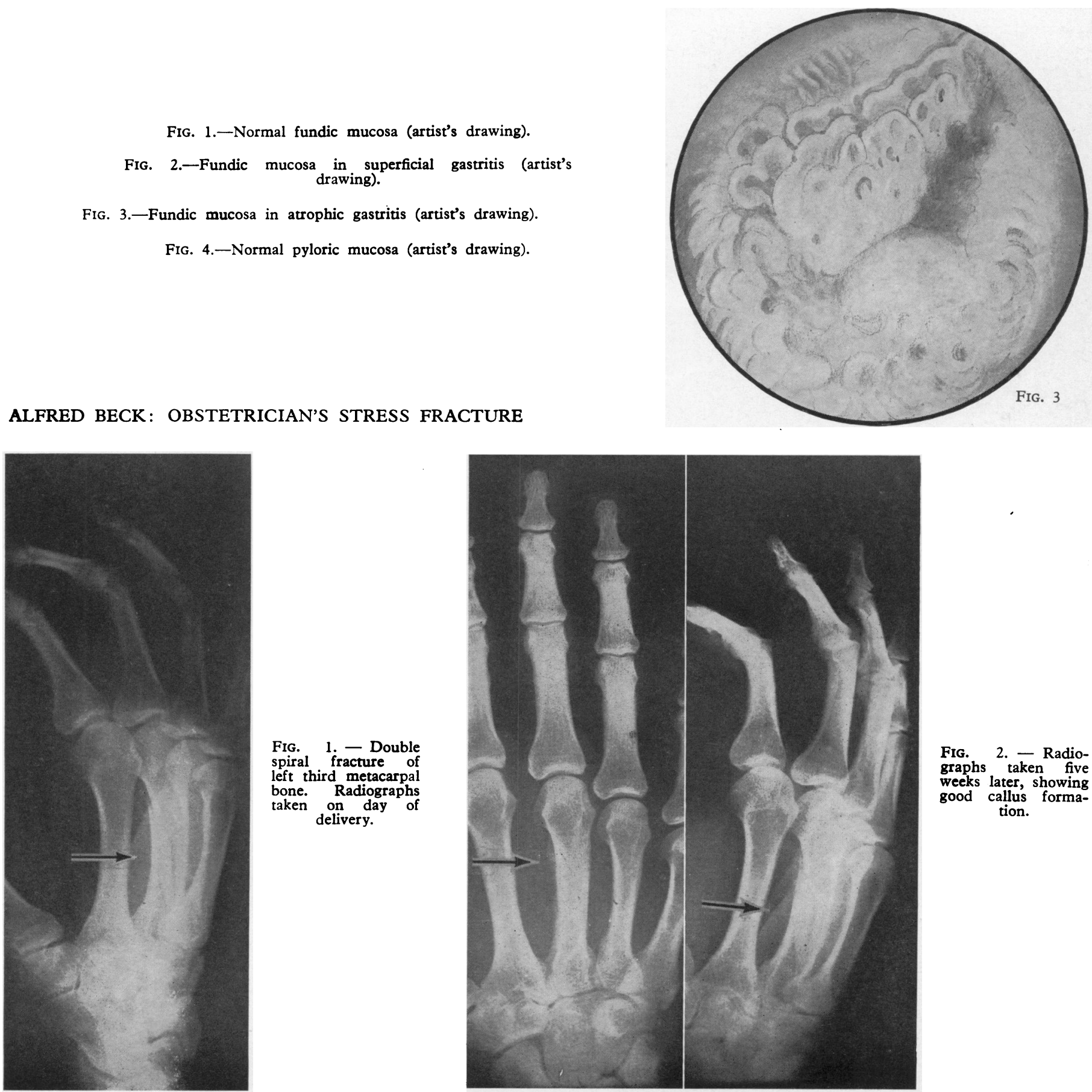

Fig. 1. - Double spiral fracture of left third metacarpal
bone. Radiographs taken on day of
delivery.

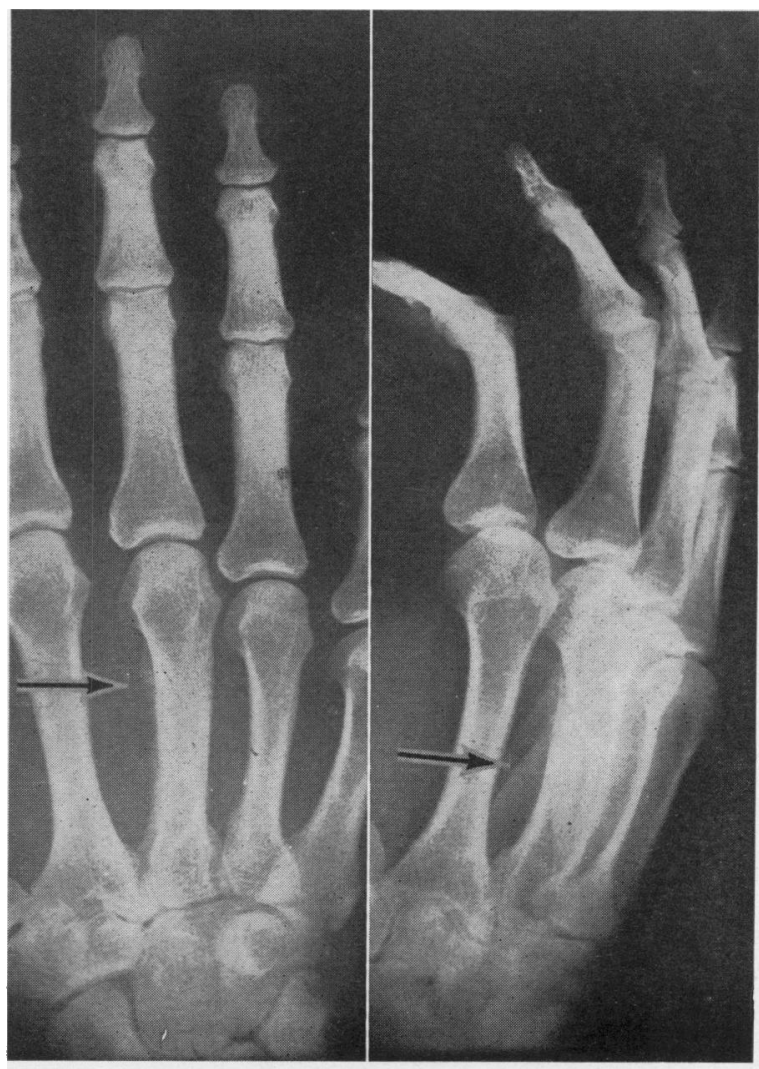

FIG. 2. - Radiographs taken five weeks later, showing good callus forma-

tion. 
regarding the arterial supply as well as the venous phase. If a hepatoma with secondary portal-vein thrombosis is suspected then it is the procedure of choice, for hepatoma and secondary neoplasm in the liver are supplied exclusively by the hepatic artery (Breedis and Young, 1954). The question will arise of which of the arteries should be catheterized. This has to be decided individually. If the only information required is whether the portal vein is patent, then the superior mesenteric artery is the one to choose, since this is generally easier than coeliac-axis catheterization and consistently affords a high concentration of contrast in the portal vein.

On the other hand, coeliac arterioportography shows the splenic as well as the portal vein and is the better procedure if an arterial lesion such as hepatoma or the very rare splenic arteriovenous aneursym (Murray, Thal, and Greenspan, 1960 ) is suspected. We have not tried the technique described by Boijsen et al. (1963) in which both vessels are catheterized and contrast is injected simultaneously. This results in passage of contrast medium into all branches of the portal system and should provide maximal contrast in the portal vein, but the use of two catheters must undoubtedly lengthen the procedure and does not appear to be justified routinely.

Finally, it is necessary to emphasize that arterioportography is a safe procedure, the only risk being that of a percutaneous femoral puncture. The wider availability of this procedure means that no patients with portal hypertension need now be operated on in whom the portal venous system has not been completely visualized pre-operatively.

\section{Summary}

A technique of arterioportography is described for use with standard $x$-ray equipment. In $36(86 \%)$ of the 42 patients examined the artery was successfully catheterized and in 26 $(72 \%)$ of them good visualization of the portal venous system was obtained. Superior mesenteric arterioportography is of particular value in the pre-operative assessment of patients with portal hypertension in whom the spleen has been removed. Coeliac arterioportography is technically more difficult and the indications for its use are considered.

We thank Professor Sheila Sherlock and Dr. W. B. Young for their encouragement and advice. We would also like to thank $\mathbf{M r}$. John Hendley and the radiographers, especially Miss B. Whittal, for technical assistance.

\section{REFERENCES}

Bierman, H. R., Steinbach, H. L., White, L. P., and Kelly, K. H. (1952). Proc. Soc. exp. Biol. (N.Y.), 79, 550 .

Boijsen, E., Ekman, C.-A., and Olin, T. (1963). Acta chir. scand., 126, 315 .

Breedis, C., and Young, G. (1954). Amer. 7. Path., 30, 969.

Ekman, C.-A. (1957). Acta chir. scand., Suppl. No. 222.

Ekman, C.-A. (1957). Acta chir, scand.,

Michels, N. A. (1942). Amer. F. Anat., 70, 21.

Murray, M. J., Thal, A. P., and Greenspan, R. (1960). Amer. F. Med., 29, 849.

Ödman, P. (1956). Acta radiol. (Stockh.), 45, 1.

(1958). Ibid., Suppl. No. 159.

Parks, A. G., and Couch, R. S. C. (1962), Lancet, 1, 136

Rigler, L. G., Olfelt, P. C., and Krumbach, R. W. (1953). Radiology, 60, 363.

Seldinger, S. I. (1953). Acta radiol. (Stockh.), 39, 369.

Tori, G. (1953). Ibid., 39, 89.

Ziedses Des Plantes, B. G. (1961). 7. belge Radiol., 43, 72.

\title{
Dissecting Microscope Appearances of the Gastric Mucosa
}

\author{
S. N. SALEM,*† M.B., CH.B., M.R.C.P.ED.; S. C. TRUELOVE,* M.D., F.R.C.P.
}

[With Special Plate]

Brit. med. F., 1964, 2, 1503-1504

Since the introduction by Wood et al. (1949) of a simple and safe instrument for peroral gastric biopsy, this method or some modification of it has been widely used to study the pathology of the gastric mucosa. Although many histological studies of gastric biopsy specimens have been made, we have been unable to find any account of the changes visible in such biopsy specimens when they are examined under a dissecting microscope.

In the course of a study of the gastric and small-intestinal changes in ulcerative colitis (Salem et al., 1964a, 1964b) we took the opportunity to study some of the gastric biopsy specimens under the dissecting microscope and to compare the appearances with the results of subsequent histological examination.

\section{Results}

The gastric biopsy specimens were obtained by means of a Crosby-Kugler capsule, which was introduced for smallintestinal biopsy (Crosby and Kugler, 1957) but has also been found convenient for gastric biopsy (Floch and Sheehy, 1962; Salem et al., 1964a). The specimens from 48 patients have

\footnotetext{
* Nuffield Department of Clinical Medicine, University of Oxford. From the Radcliffe Infirmary, Oxford.

† Physician in the Kuwait Government Medical Service on study leave.
}

been examined under the dissecting microscope; in some patients separate specimens were obtained from the cardia, the body, and the pyloric end of the stomach under fluoroscopic control using an image intensifier and television monitor.

We found that the appearances of the fundic mucosa under the dissecting microscope varied from specimen to specimen and that three main categories could be recognized which corresponded to various histological appearances. The three categories are as follows:

Category I (corresponding to normal histological appearances).--Under the dissecting microscope there is a uniformly regular pattern of papillae, each one of which has a round hole in its centre, representing the mouth of a gastric gland. The papillae are packed close together. The colour varies from a pale pink to a faint red. The general appearance can be compared to that of a honeycomb, or Morocco leather (Special Plate, Fig. 1).

Category II (corresponding to superficial gastritis on histological examination).-The papillae are swollen, congested, and reduced in number. The gastric-gland openings are slit-like and look deep, owing to surrounding swelling (Special Plate, Fig. 2). Hyperaemia is often obvious. (Sometimes patches of mucosa with these characteristics are interspersed with normal areas, just as histologically the appearances of superfioial gastritis may be patchy.) 
Category III (corresponding to atrophic gastritis or mucosal atrophy on histological examination).- There are irregular, broad, leaf-shaped mucosal folds and convolutions which are sometimes arranged in the form of rosettes (Special Plate, Fig. 3). The openings of gastric glands are usually invisible. (Note that particular attention should be given to the periphery of the specimen when studying these appearances.)

\section{Appearances of Normal Pyloric and Cardiac Mucosa}

These are different from those of normal fundic mucosa. In pyloric mucosa, the mucosa is arranged in a uniform mosaic or fish-scale pattern, with several normal papillae in each part of the pattern (Special Plate, Fig. 4). The cardiac mucosa is similar but the pattern is less coarse, with fewer papillae in each subdivision.

In gastritis the pattern is commonly similar to that of category III of the fundic mucosa.

\section{Discussion}

Holmes et al. (1961) were the first to point out that examination of a small-intestinal biopsy specimen permitted immediate recognition of normal villi, abnormal villi, or the flattened mucosa of subtotal villous atrophy. Subsequent work has confirmed the validity of this observation, and we have found the method useful in our own studies (Salem et al., 1964a).

In a similar fashion, it appears that inspection of a gastric biopsy specimen under the dissecting microscope enables the diagnosis of gastritis to be made immediately. If the gastritis is patchy, as in some examples of chronic superficial gastritis, this fact is immediately evident and may be a guide to subsequent choice of area for histological examination.

\section{Summary}

Gastric biopsy specimens from 48 patients have been examined under the dissecting microscope and the appearances correlated with subsequent histological findings.

The fundic mucosal appearances can be divided into three categories which correspond to normal histology, chronic superficial gastritis, and atrophic gastritis or gastric mucosal atrophy. The agreement between the dissecting-microscope appearances and the histological examination is almost perfect.

Normal pyloric mucosa and cardiac mucosa each differ from normal fundic mucosa under the dissecting microscope but show analogous changes when there is gastritis.

Examination of a gastric biopsy specimen under the dissecting microscope therefore permits of the immediate diagnosis of gastritis with a high measure of confidence.

\section{REFERENCES} Crosby, W. H., and Kugler, H. W. (1957). Amer. F. dig. Dis., 2, 236.
Floch, M. H., and Sheehy, T. W. (1962). Gastroenterology, 43, 32. Holmes, R., Hourihane, D. O'B., and Booth, C. C. (1961). Lancet, 1, 81. Salem, S. N., Truelove, S. C., and Richards, W. C. D. (1964a). Brit. med. F., 1, 394.

Wo

Wood, I. J., Doig, R. K., Motteram, R., and Hughes, A. (1949). Lancet, 1,18 .

\title{
Red-cell Aplasia with Carcinoma of the Bronchus
}

\author{
C. C. ENTWISTLE,* м.B., CH.B. ; P. H. FENTEM,* M.SC., M.B., CH.B. ; A. JACOBS,* M.D., M.C.PATH.
}

The literature contains 83 reports of pure red-cell aplasia (Andersen and Ladefoged, 1963 ; Schmid, Kiely, Pease, and Hargraves, 1963). An association with a thymic tumour has been demonstrated in 44 cases, but the condition has not been described with other tumours. The present report describes a patient in whom red-cell aplasia occurred together with a bronchial carcinoma. The serum of this patient contained a factor which inhibited erythropoiesis in rabbits but which was absent after irradiation of the tumour.

\section{Case Report}

A man aged 68 attended his doctor for a routine medical examination prior to his retirement from a job as a labourer in the engineering industry. He was found to be pale and was referred to Cardiff Royal Infirmary in February 1961 for investigation. His only complaint was that of tiredness. He had smoked at least 20 cigarettes each day for many years and had experienced a productive cough for three years.

Physical examination confirmed the mucosal pallor. His spleen was palpable on deep inspiration but there were no other abnormal physical signs.

Investigations.-Haemoglobin 6.7 g. $/ 100 \mathrm{ml}$. M.C.H.C. $32 \%$. M.C.V. 140 cubic microns. Reticulocyte count $1 \%$. W.B.C. 3,900 /

* From the Medical Unit and Department of Pathology, Welsh National School of Medicine, Cardiff Royal Infirmary. c.mm., normal differential count. Platelets $265,000 /$ c.mm. Blood film: normochromic macrocytic red cells, with anisocytosis and poikilocytosis. E.S.R. $50 \mathrm{~mm}$. in 1 hour (Westergren). Direct Coombs test negative. Serum vitamin $B_{12} 141 \mu \mu \mathrm{g} . / \mathrm{ml}$. Serum proteins: total $6.7 \mathrm{~g} . / 100 \mathrm{ml}$. (albumin $4.0 \mathrm{~g}$.). Blood urea $33 \mathrm{mg} . /$ $100 \mathrm{ml}$. Sternal marrow aspirate showed only scanty red-cell precursors, which were normoblastic in type. They comprised $4 \%$ of the total cells. The myeloid series and megakaryocytes were normal. Trephine marrow biopsy from the iliac crest showed slight hypocellularity. Gastric analysis revealed a histamine-fast achlorhydria. Barium-enema examination showed diverticulosis of the colon. Chest radiograph was normal. Faecal occult blood was negative.

The patient made no response to injections of vitamin $B_{12}$ and was believed to have a hypoplastic anaemia. He required blood transfusions to prevent a serious fall in haemoglobin, and during the next 21 months he received 60 pints ( 34 litres) of blood.

Three months after his first admission to hospital he developed a transient pyrexial illness with a polyarthritis involving the lumbar spine, ankles, knees, and hands. The pyrexia responded to penicillin. The cause of the illness was uncertain. His E.S.R. reached $150 \mathrm{~mm}$. in 1 hour (Westergren) but his peripheral white-cell count remained within normal limits. Serum electrophoresis at this time showed a raised gamma-globulin. Shortly after this illness clubbing of the finger-nails was noted for the first time.

In August 1962 the patient's haemoglobin was $11.5 \mathrm{~g} . / 100 \mathrm{ml}$., M.C.H.C. $33 \%$, with the aid of transfused blood. The reticulocyte count was $20,400 /$ c.mm. and had been at about this level for the previous year. Serum iron was $203 \mu \mathrm{g} . / 100 \mathrm{ml}$. and total iron- 